This is the postprint (accepted manuscript) version of the article published by ACS in the journal Environmental Science and Technology. The journal edited version is available on-line at: https://doi.org/10.1021/acs.est.8b03725

\title{
Modeling dispersal of UV filters in estuaries
}

\section{David Lindo-Atichati, ${ }^{,+t,}, \uparrow$ Pedro Montero, ${ }^{\S}$ Rosario Rodil, $\|$ José Benito}

\section{Quintana,\| and Manuel Miró ${ }^{\perp}$}

$\dagger$ Department of Engineering and Environmental Science, The City University of New York, Staten Island, NY USA

$\ddagger$ Department of Earth and Planetary Sciences, American Museum of Natural History, New York, NY USA

IDepartment of Applied Ocean Physics and Engineering, Woods Hole Oceanographic Institution, Woods Hole, MA USA

§INTECMAR, Xunta de Galicia, Vilagarcía de Arousa, Spain

|l Department of Analytical Chemistry, University of Santiago de Compostela, Santiago de Compostela, Spain

$\perp$ FI-TRACE group, Department of Chemistry, University of the Balearic Islands, Carretera de Valldemossa km 7.5, E-07122 Palma de Mallorca, Spain

\section{E-mail: dlindo@whoi.edu}

\begin{abstract}
Lagrangian ocean analysis, where virtual parcels of water are tracked through hydrodynamic fields, provides an increasingly popular framework to predict the dispersal of water parcels carrying particles and chemicals. We conduct the first direct test of Lagrangian predictions for emerging contaminants using: (1) the latitude, longitude, depth, sampling date, and concentrations of UV filters in raft cultured mussel (Mytilus galloprovincialis) of the estuary Ria de Arousa, Spain $\left(42.5^{\circ} \mathrm{N}, 8.9^{\circ} \mathrm{W}\right)$; (2) a hydrodynamic numerical model at $300 \mathrm{~m}$ spatial resolution; and (3) a Lagrangian dispersion
\end{abstract}


scheme to trace polluted water parcels back to pollution sources. The expected dispersal distances (mean $\pm \mathrm{SD}$ ) are $2 \pm 1 \mathrm{~km}$ and the expected dispersal times (mean \pm SD) are $6 \pm 2$ h. Remarkably, the probability of dispersal of UV filters from potential sources to rafts decreases fivefold over $5 \mathrm{~km}$. In addition to predicting dispersal pathways and times, this study also provides a framework for quantitative investigations of concentrations of emerging contaminants and source apportionment using turbulent diffusion. In the coastline, the ranges of predicted concentrations of the UV-filters 4-methylbenzylidene-camphor, octocrylene, and benzophenone- 4 are $3.2 \cdot 10^{-4}-0.023$ $\mathrm{ng} / \mathrm{mL}, 2.3 \cdot 10^{-5}-0.009 \mathrm{ng} / \mathrm{mL}$, and $5.6 \cdot 10^{-4}-0.013 \mathrm{ng} / \mathrm{mL}$, respectively. At the outfalls of urban wastewater treatment plants these respective ranges increase to $8.9 \cdot 10^{-4}-0.07$ $\mathrm{ng} / \mathrm{mL}, 6.2 \cdot 10^{-5}-0.027 \mathrm{ng} / \mathrm{mL}$, and $1.6 \cdot 10^{-3}-0.040 \mathrm{ng} / \mathrm{mL}$.

\section{INTRODUCTION}

Understanding patterns of dispersal of organic contaminants in aquatic environments is a major goal of twenty-first century environmental science and technology ${ }^{1-4}$. These patterns determine the probability of contamination, and the pathways between pollution sources and extremely valuable aquatic ecosystems ${ }^{5,6}$. The pathways of contaminants, in turn, have major implications for understanding environmental and health risks, and developing monitoring and mitigation strategies ${ }^{7-9}$.

The propagation of persistent organic pollutants (POPs) in natural environments has emerged as a major issue for the last six decades. Persistent legacy organic contaminants (LOCs) include, for example, polycyclic aromatic hydrocarbons and polychlorinated biphenyls. Due to their persistence, bioaccumulation, and environmental health risks ${ }^{10}$, LOCs have been banned or severely restricted under international regulations ${ }^{11}$. While LOCs are still under close environmental scrutiny, the past two decades have also witnessed the advent of POPs of concern. Persistent emerging organic contaminants (EOCs) encompass a variety of bioaccumulative chemicals that are not covered by existing water-quality 
regulations, and have the potential to enter the environment and cause adverse ecological and (or) human health effects ${ }^{12-14}$. EOCs enter natural waters through urban and industrial sewage, erosional runoff, leaching from agricultural areas and effluents of wastewater treatment plants ${ }^{15}$, as they are not entirely removed by conventional wastewater treatment technologies. After their release into the aquatic environment, EOCs can reach several environmental compartments including soil, groundwater, air, and biota ${ }^{16,17}$. Their persistence in the aquatic environment has the potential to cause adverse ecological and human health effects as bioaccumulated EOCs are potentially carcinogenic, mutagenic, toxic for reproduction, or act as endocrine disrupters ${ }^{12,18}$. Nevertheless, it is not until recently that joint efforts have been made by the research community to provide a comprehensive list of EOCs that embraces more than 700 pollutants, their metabolites and transformation products ${ }^{6,19,20}$. The EOCs on this list include UV filters associated with the growth of tourism activities ${ }^{16,21}$. Despite recent research efforts to integrate EOCs into hydrodynamic models ${ }^{22}$, the paucity of real in situ data has limited the incorporation of EOCs data into physical models to study their transport and fate ${ }^{8}$.

The raft cultured blue mussel (Mytilus galloprovincialis) model offers a tractable system to investigate the mechanism by which EOCs are dispersed from potential sources to aquaculture sites. Raft mussels represent an extreme case of aggregation in which individuals live along suspended growth ropes ${ }^{23,24}$. In any given population of raft cultured $M$. galloprovincialis, the location of the raft is known, tissue of individuals can be collected, concentrations of different analytes can be determined by liquid chromatography-mass spectrometry (LC-MS) and gas chromatography-mass spectrometry (GC-MS) approaches ${ }^{25-27}$, and concentrations of analytes can be averaged (see the Supporting Information). Because we found the concentrations of UV filters to be the highest across EOCs in mussels, we chose UV filters as the representatives EOCs for this work. Data of contaminants found in the aquatic environment can be incorporated into a particle dispersion model that, coupled with a hydrodynamic numerical model, allows us to trace polluted water parcels from sources to 
potential destination sites and vice versa ${ }^{28}$. The outputs of these Lagrangian models are 3D coordinates of the polluted water parcels through time, thus enabling the computation of dispersal distances, dispersal times, and connectivity matrices. The validity and state of the Lagrangian integrated modeling approach has been recently reviewed by van Sebille et al. $2017^{29}$. For example, a better understanding of the relative effects of hydrodynamic, thermodynamic, and geochemical factors on the fate and transport of oil plumes in the subsea can be achieved by incorporating experimental and in situ data into Lagrangian modeling frameworks ${ }^{30}$. Although water quality models have been already applied to persistent organic pollutants (e.g. O'Driscoll et al. $2013^{31}$ ), few models have addressed the fate and transport of emerging contaminants due to the limited available data ${ }^{22}$. Here, we incorporate these data into a stochastic Lagrangian model that is coupled with a high-resolution hydrodynamic model to generate the expected trajectories of water parcels that transport EOCs between pollution sources and mussel rafts that have been exposed. These results enable us to derive dispersal distances, directions, times, expected concentrations of EOCs at the shoreline, and the possible contamination sources and mechanisms that control the transport and fate of dissolved contaminants in estuaries.

This is the first time that a particle tracking model is combined with chemical analysis of organic contaminants in biota to track the sources and apportionment of EOCs in estuarine settings.

\section{MATERIALS AND METHODS}

\section{Study Site}

The Galician Rias are a group of coastal embayments located in the West of Galicia (NW Spain). They are situated along the northern boundary of the NW Africa upwelling system $^{32,33}$. This fact together with the regional orography, has led Galician Rias to be the second largest producer of blue mussel in the world, with nearly 267,000 tn annually ${ }^{34}$. The 
culture consists of wooden raft moorings with a maximum of 500 hanging ropes of a maximum length of $12 \mathrm{~m}$ where mussels grow. There are about 3,340 mussel rafts scattered across the Galician Rias, most of them (around 2,300) in Ria de Arousa. This funnel-shaped estuary has an average channel width of $9 \mathrm{~km}$ and a total channel length from mouth to the most distant headwater tributary of $33 \mathrm{~km}$. The inner part of the ria is less than $20 \mathrm{~m}$ deep while, in the outer part of the ria, Salvora island divides the oceanic entrance into a narrow and shallow northern mouth of approximately $10 \mathrm{~m}$ deep and a wider and deeper southern mouth, approximately $55 \mathrm{~m}$ deep ${ }^{35}$. This study was conducted using 67 locations of potential sources of EOCs, and samples from a population of the raft cultured mussel collected during four different seasons at 2 locations of Ria de Arousa (Figure 1).

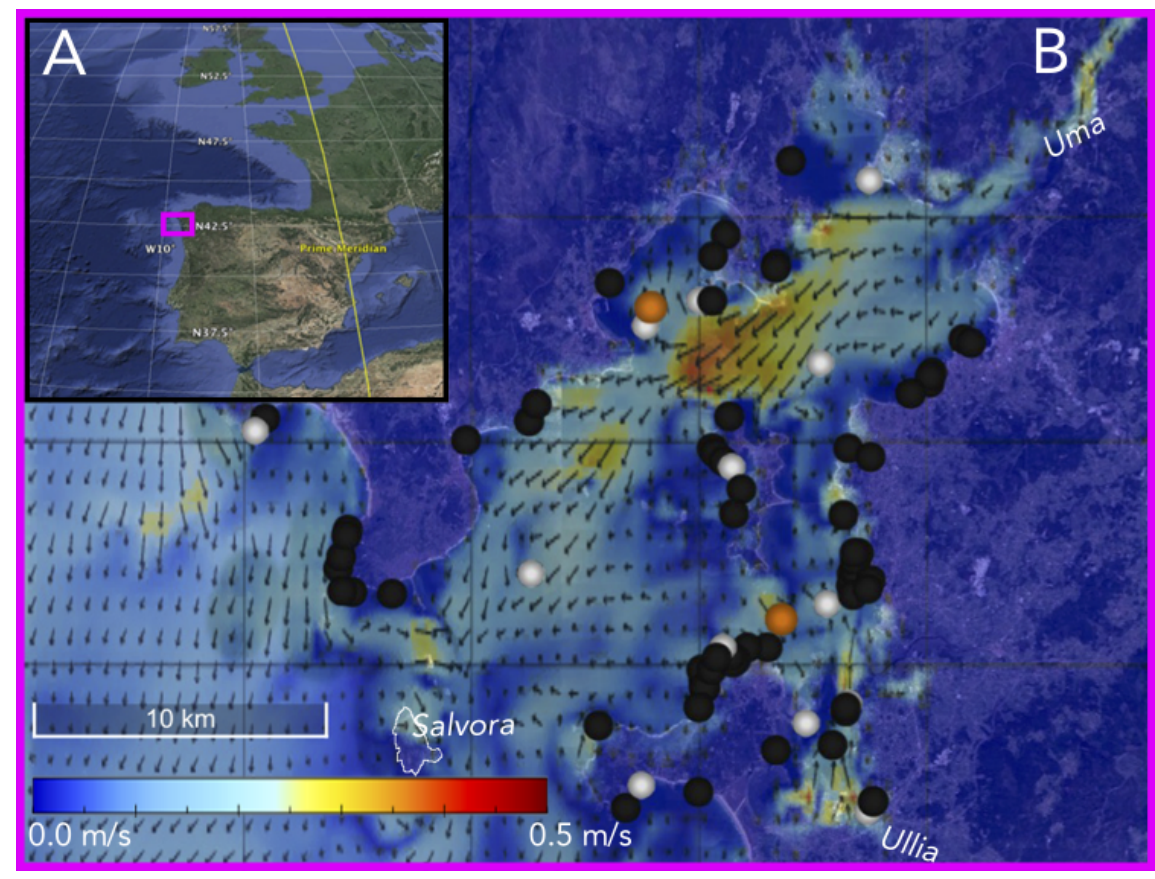

Figure 1: (a) Location of Ria de Arousa in the eastern North Atlantic. (b) Location of 2 mussel rafts (orange circles), marine outfalls of 11 wastewater treatment plants (white circles), and 56 industrial wastewater discharges (black circles) in Ria de Arousa.

The oceanographic structure of the ria is usually classified as a partially mixed. The tidal forcing is mainly semidiurnal with M2 amplitude of about $1.1 \mathrm{~m}$ modulated over the springneaps cycle by $\mathrm{S} 2$ and $\mathrm{N} 2$ amplitudes of about $0.3 \mathrm{~m}^{36}$. The two main rivers that discharge into this ria are the Ulla and the Umia, which have lower discharge rates in summer than in 
any other season. In winter, stratification is determined by the river freshwater input while, in contrast with the classical definition of estuaries, stratification in summer is caused by solar heating ${ }^{37}$.

The oceanographic circulation of the ria is driven by the succession of upwelling and downwelling events driven by the dominant shelf winds interacting with topography. Offshore northerly winds induce upwelling, increase stratification, and prevail from March to October. Onshore southerly winds induce downwelling, reduce stratification, and dominate the rest of the year. During upwelling winds, sub-surface central water intrudes as a lower layer into the ria; during downwelling winds this colder lower layer disappears from the ria as oceanic surface waters flow into the $\mathrm{ria}^{38-40}$. This seasonality mirrors the seasonally varying changes in the strength and position of the atmospheric pressure cells that govern the North Atlantic climatology, the Azores High and the Greenland Low, defining two wind-featured oceanographic seasons. It is likely that local direct winds, including diurnal cycles play a secondary role ${ }^{35}$. Apart from their role in vertical mixing, tidal excursions are dominant in the innermost ria ${ }^{41,42}$, but they likely play a minor role in longitudinal exchange in the middle ria where tidal excursions are less than $5 \mathrm{~km}$ due to the widening (narrowing) of the middle (inner) region of the ria ${ }^{41}$.

\section{Mussel Sampling and Lagrangian Tracking}

M. galloprovincialis were collected from two mussel rafts located in the inner part of Ria de Arousa; a northern mussel raft located $1,450 \mathrm{~m}$ offshore at $42.61^{\circ} \mathrm{N}, 8.91^{\circ} \mathrm{W}$; and a southern mussel raft located $1,550 \mathrm{~m}$ offshore at $42.51^{\circ} \mathrm{N}, 8.85^{\circ} \mathrm{W}$. The average depth of the ropes where mussels grow is $6 \mathrm{~m}$. Samples at the northern location were collected on January 31, 2012; May 14, 2012; August 23, 2012; and November 7, 2012. Samples at the southern location were collected on February 2, 2012; May 14, 2012; August 23, 2012; and November 8, 2012. These dates are used as the initial times for the backtracking Lagrangian simulation. A map of likely trajectories of UV filters was generated at the former sampling locations and 
dates, and trajectories were tracked backward in time for 10 days

\section{Hydrodynamic model component}

In order to obtain current velocity fields to force the Lagrangian model in Ria de Arousa, we used the hourly outputs of a high resolution, operational model run by the Galician meteorological service MeteoGalicia (www.meteogalicia.gal). The Oceanographic Operational System implemented by MeteoGalicia consists of two nested levels of hydrodynamic models that run daily ${ }^{43}$. The largest grid is modeled by the Regional Ocean Modeling System (ROMS) ${ }^{44}$, which covers the Northern Iberian Peninsula $\left(38-46^{\circ} \mathrm{N}, 4-14^{\circ} \mathrm{W}\right)$, with a horizontal spatial resolution of $1 / 50^{\circ}$ (ca. $2.2 \mathrm{~km}$ ) and 41 vertical layers. Baroclinic lateral boundary conditions are prescribed by the Iberia Biscay Irish ocean forecast model distributed by Copernicus Marine Environment Monitoring Service ${ }^{45}$, with a horizontal spatial resolution of $1 / 36^{\circ}$ (ca. $3.1 \mathrm{~km}$ ) and 50 vertical layers. Tidal data is provided by OSU TOPEX/Poseidon Global Inverse Solution $^{46}$. The ROMS model provides lateral boundary conditions for several higher resolution grids covering Rias of Artabro, Muros, Arousa, and Pontevedra/Vigo. At this level, the water modeling system is MODelo HIDrodinâmico (MOHID, www.mohid.com) ${ }^{47}$. MOHID is an open-source free-surface, baroclinic regional circulation model developed by MARETEC, a research group at University of Lisbon, Portugal. The model uses incompressibility, hydrostatic, Boussinesq, and Reynolds approximations to solve the 3-dimensional Navier-Stokes equations. Vertical velocities are computed through the continuity equation integrated over the entire water column. The turbulent vertical mixing is solved by mean of the General Ocean Turbulence Model (GOTM, http://www.gotm.net). The spatial discretisation is implemented using a finite-volume method, solved in an Arakawa C-grid structure, with horizontal resolution of $1 / 300^{\circ}$ (ca. $300 \mathrm{~m}$ ), 35 vertical layers, and time step of 30 s. Surface boundary conditions for winds and atmospheric fluxes are prescribed by the Weather Research and Forecasting (WRF, https://www.mmm.ucar.edu/weather-researchand-forecasting-model) model, which is run by MeteoGalicia at $12 \mathrm{~km}$ resolution for ROMS 
and at $4 \mathrm{~km}$ resolution for MOHID twice a day. Daily averages of flow and temperature of the main rivers -Miño, Verdugo, Lerez, Umia, Ulla, Tambre and Eume- were provided by the Soil Water Assessment Tool (SWAT, http://swatmodel.tamu.edu) to feed both hydrodynamic models. In the case of Ria de Arousa grid, in addition to Ulla and Umia rivers inputs, minor tributaries are taken into account. An accurate bathymetry was constructed based on data from the Spanish Navy Hydrographic Institute. MOHID has been extensively calibrated and validated with MyOcean product Sea Ultra High Resolution Sea Surface Temperature Analysis, Argo floater data from IFREMER (French Research Institute for Exploration of the Sea) and data sets from coastal monitoring programs in the western Iberian coast ${ }^{47,48}$.

The MOHID archives used herein for the Lagrangian simulations consist of the threedimensional current velocity fields for January 31 to February 22, 2012; May 14 to May 24, 2012; August 23 to September 2, 2012; and November 7 to November 18, 2012.

\section{Lagrangian model component}

The methodology followed in this study to model dispersal of UV filters is similar to the Lagrangian methodology presented by Lindo-Atichati et al. 2016. Broadly, Lagrangian ocean analysis is aimed at estimating the trajectory of virtual fluid particles by making use of Eulerian fluid information, i.e., the velocity field. Alternatively, the Eulerian approach is based on describing fluid motion in a reference frame that is fixed in space, enabling accurate computation of concentrations but not enabling the tracking of fluid parcels. Both Lagrangian and traditional Eulerian modeling approaches are robust methods, under a computational point of view, to simulate the dispersion of pollutants ${ }^{22,31}$. Lagrangian models generally give more accurate results in terms of identification of ocean eddy and coherent features ${ }^{50,51}$ while Eulerian models demand a significantly lesser computational time ${ }^{50}$. Here, MOHID provided estimates of 3-D currents to the open-source Lagrangian framework Parcels ${ }^{28}$, which is aimed at Lagrangian analyses and designed to be efficient for the new generation of ocean circulation models in the petascale age ${ }^{29}$. At its core, computing Lagrangian trajectories is 
equivalent to solving the following equation:

$$
X(t+\Delta t)=X(t)+\int_{t}^{t+\Delta t} v(x, \tau) d \tau+\Delta X_{s}(t)
$$

where $X(t)$ is the three-dimensional position of a water parcel — carried by isopycnal and vertical transports from the average depth of the mussel raft - and $v(x, \tau)$ represents the three-dimensional Eulerian velocity field from MOHID at that position. $\Delta X_{s}(t)$ is a change in position due to stochastic noise that is added to the horizontal motion of water parcels to represent subgrid scale motions following the random walk model (i.e., a zeroth-order Markov process $)^{52}$. Due to that stochastic noise - a diffusivity term that accounts for the subgrid scale eddies not resolved by the model - we obtain a map of likely trajectories in a probabilistic (not deterministic) fashion. The trajectory Eq. (1) is time-stepped using a fourth-order Runge-Kutta scheme.

Because ocean currents are highly variable both spatially and temporally and because sub-mesoscale flows are chaotic in nature, two water parcels deployed simultaneously at the same location often follow very different paths ${ }^{53}$. Also, because of the inherent chaotic nature of nonlinear advection and the unresolved subgrid-scale processes in MOHID, it is only statistically that the modeled flows can be compared to the real world flows ${ }^{54}$. To account for this indeterminacy, we produced an envelope of likely trajectories by generating hourly releases of 100 synthetic water parcels ${ }^{55}$ at each location of the mussel raft and at the average depth of the mussel rope during the $24 \mathrm{~h}$ of the in situ sampling dates, generating 2,400 trajectories per mussel raft, 4,800 trajectories per sampling day $(2,400$ trajectories x 2 mussel rafts), and 19,200 trajectories for the four sampling dates (4,800 trajectories x 4 sampling dates) (Figure 2). Synthetic water parcels containing UV filters were tracked backward in time for 10 days using an integration time step of $10 \mathrm{~min}$. Pathways of simulated trajectories were terminated when reaching a shoreline, the bottom topography boundary, or the 10 days limit, whichever occurred first. 


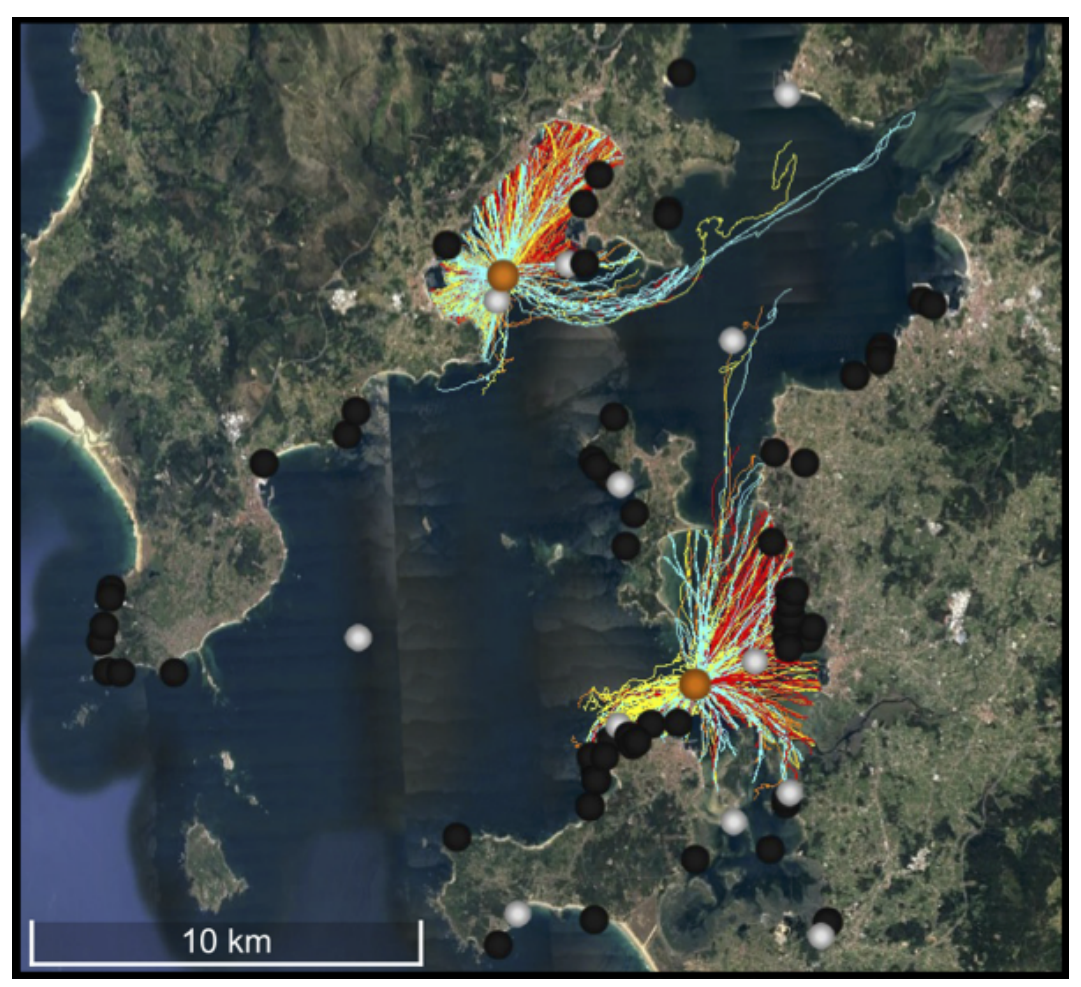

Figure 2: Simulated trajectories of water parcels released hourly at the mussel rafts locations (orange circles) on February 2, 2012 (cyan); May 14, 2012 (yellow); August 23, 2012 (red); and November 8, 2012 (orange). Trajectories are tracked backward in time for 10 days. To facilitate visualization, only 500 trajectories are represented. Orange, white and black circles depict the location of 2 mussel rafts, marine outfalls of 11 wastewater treatment plants, and 56 industrial wastewater discharges.

\section{Statistical analyses}

To generate an expected distribution of dispersal distances we estimated the shortest distance between the coordinates of the mussel rafts and the coordinates where the contaminants are predicted to be originated. Further, the 19,200 pairs of coordinates from the backtracking study were used to estimate the actual distribution of dispersal directions and the distribution of dispersal times.

We used a repeated measures permutational multivariate analysis of variance (RMPERMANOVA ${ }^{56}$ to test for differences in distributions of dispersal distance, direction, and time between between sampling locations and among sampling seasons. All multivariate statistical analyses were carried out in the R environment (www.r-project.org), using the 
vegan package (https://github.com/vegandevs/vegan).

To explore the independent effect of sampling location on distance and direction of dispersal of UV filters we used bivariate polar graphs. Working in polar coordinates helps to understand the directional dispersal dependence of different locations. For example, these graphs show how the contaminants' direction of origin and distance varied in the northern and southern location of Ria de Arousa. A Generalized Additive Model (GAM) is used to derive smooth surfaces for all bivariate polar graphs using the 'openair' open source tools ${ }^{57}$.

For brevity, we defined the useful combination of dispersal and eventually reaching the coastline by polluted water parcels as 'beaching'. We tested the hypothesis that the probability of beaching will decline as a function of dispersal distance, direction, and time using a logistic model (JMP v. 14.0.1). The probability of beaching between the sampled mussel rafts and coastline locations (0 or 1 ) was used as the dependent variable, whereas distance (continuous), and direction (continuous) between the sampled mussel rafts and the coastline were assumed as independent variables. This approach enabled us to test for the effect of one variable (e.g. distance) while controlling statistically for the effect of other variables (e.g. direction), and explore the effect of interactions between variables. Independent variables were removed from the model in a backward stepwise fashion if they did not have a significant effect. We confirmed that the model generated this way was the same as the model generated using a forward stepwise approach.

\section{Model application}

Finally, we carried out an exercise that tested the suitability of this work for real life applications. Using (1) turbulent diffusion theory for estuaries and coastal waters, (2) the spatial distribution and temporal evolution of polluted water parcels that were backtracked in the Lagrangian simulations, and (3) the minimum and maximum concentrations of three representative UV filters found in the mussels of the southern location of the estuary, we computed estimates of the expected concentration of UV filters at the coastline and at the 
outfalls of wastewater treatment plants.

Because Lagrangian models are not designed to calculate concentrations in a reference frame that is fixed in space, we calculated the concentration at the sources by using a solution of the equation of advective transport and molecular diffusion for turbulent flows:

$$
\frac{\partial c}{\partial t}+u \frac{\partial c}{\partial x}+v \frac{\partial c}{\partial y}+w \frac{\partial c}{\partial z}=D\left(\frac{d^{2} c}{d x^{2}}+\frac{d^{2} c}{d y^{2}}+\frac{d^{2} c}{d z^{2}}\right)
$$

where $c$ is the mass concentration, $t$ is time, $u$ is the velocity on the $\mathrm{x}$-direction, $v$ is the velocity on the y-direction, $w$ is the velocity on the z-direction, and $D$ is the molecular diffusion coefficient. The advective-diffusion equation is solved for estuaries and coastal waters assuming continuous line source of finite length ${ }^{58}$ as sketched in Figure 3 . This assumption is usually taken when wastewaters are discharged from outfalls with fairly long diffusers into essentially unbounded waters such as a wide estuary or coastal waters ${ }^{59}$.

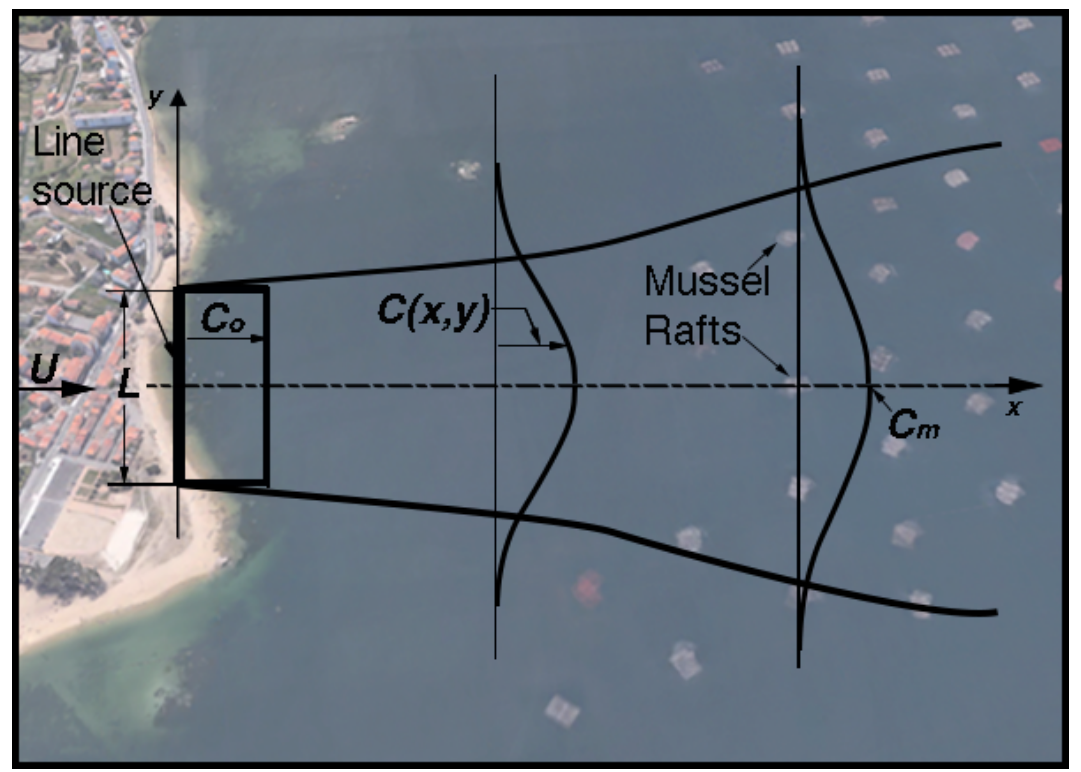

Figure 3: Diffusion of a contaminated fluid from a continuous line source of finite length $L$ to mussel rafts of know concentration of UV filters $C_{m}$.

For this case, the advective-diffusion equation, Eq. 2, can be formulated as:

$$
u \frac{\partial c}{\partial x}=\frac{\partial}{\partial x}\left(\epsilon_{y} \frac{\partial c}{\partial y}\right)
$$


where $\epsilon_{y}$ is the diffusion coefficient on the y-direction. We assumed steady-state conditions, neglected diffusion in the $\mathrm{x}$ - and z-directions, and neglected bacterial decay. Solutions to Eq. 3 for various assumptions about the variation of $\epsilon_{y}$ were obtained by Brooks $1960^{60}$, and derived for estuaries and coastal waters by Roberts and Webster $2002^{58}$ obtaining the following equations:

$$
\begin{gathered}
C_{o}=C_{m} S_{f} \\
S_{f}=\left[\operatorname{erf}\left(\frac{3 / 2}{\left(1+8 \alpha L^{-2 / 3} t\right)^{3}-1}\right)^{1 / 2}\right]^{-1}
\end{gathered}
$$

where $C_{o}[\mathrm{ng} / \mathrm{mL}$ seawater $]$ is the expected initial concentration of contaminants assumed uniform along a line source, $C_{m}[\mathrm{ng} / \mathrm{mL}$ seawater $]$ is the maximum (centerline) concentration of contaminants in water parcels located at the sampled mussel raft, $S_{f}$ is the far-field dilution, $\alpha$ is a constant depending on the energy dissipation rate that can be approximately bracketed with $0.01<\alpha<0.002 \mathrm{~cm}^{2 / 3} / \mathrm{s}$ and assumed as the upper value of $0.01 \mathrm{~cm}^{2 / 3} / \mathrm{s}, L$ is the diffuser length $[\mathrm{m}]$ at the line source, $t$ is the average dispersal time $[\mathrm{h}]$ of contaminants in water parcels from the mussel raft to the line source.

The diffuser length of the sources $(L)$ and the average dispersal times from the mussel rafts to the sources $(t)$ were obtained from the Lagrangian simulations. We considered two types of line sources; the coastline and the outfalls of urban wastewater treatment plants. The length of the coastal sources was the total distances of coastline that received polluted water parcels after 10 days of backtracking simulation. The diffuser length of the outfalls was the number of outfalls that received at least one trajectory of polluted waters after 10 days of backtracking simulation multiplied by the minimum distance around the outfalls that allows for detecting at least one trajectory. The diffuser lengths used in this work are approximate estimates of the real diffuser lenghts in the coastlines and outfalls of wastewater treatment plants. A more precise computation of these $L$ values is out of the scope of this 
manuscript.

To represent the thermodynamic equilibrium between the organism and source compartments we used the bioconcentration factor (BCF) specific for each UV filter in mussels. Organisms can attain steady-state if both the exposure and the environmental/physiological factors affecting the uptake and loss of pollutants remain constant for a sufficiently long time. Thus, $C_{m}$ can be calculated based on $\mathrm{BCF}$ as follows:

$$
C_{m}=\frac{C_{\text {mussel }}}{B C F}
$$

where $C_{\text {mussel }}[\mathrm{ng} / \mathrm{g}$ dry weight] is the measured contaminant concentration in the mussel, $B C F[\mathrm{~mL} / \mathrm{g}]$ is the measured bioconcentration factor in mussels ${ }^{61}$

We chose 4-methylbenzylidene-camphor (4-MBC: $\mathrm{C}_{18} \mathrm{H}_{22} \mathrm{O}$ ), octocrylene (OC: $\mathrm{C}_{24} \mathrm{H}_{27} \mathrm{NO}_{2}$ ), and benzophenone-4 (BP-4: $\left.\mathrm{C}_{14} \mathrm{H}_{12} \mathrm{O}_{6} \mathrm{~S}\right)$ as representative UV filters for this exercise of model application. The reason for that choice is that bioaccumulation kinetics in M. galloprovincialis $^{62}$ has been calculated, with mean BCF of $905 \mathrm{~mL} \mathrm{~g}^{-1}$ for BP-4 and 2,210 mL $\mathrm{g}^{-1}$ for OC. The 4-MBC bioaccumulation did not fit a model due to the high variability of the data and therefore we used a maximum BCF of $801 \mathrm{~mL} \mathrm{~g}^{-162}$.

\section{RESULTS AND DISCUSSION}

\section{Modeled dispersal distances, directions, and times}

Considering both sampling stations and all four sampling seasons, a total of 18,816 trajectories ended up in the coastline after 10 days of backtracking simulation. That is to say, at this spatial $(300 \mathrm{~m})$ and temporal $(1 \mathrm{hr})$ resolution, $98 \%$ of water parcels found near mussel rafts polluted with UV filters (located $c a .1,500 \mathrm{~m}$ offshore), likely originated from the coastline during the 10 days prior to collecting the mussels. The remaining $2 \%$ of polluted water parcels either emanated from polluted sediments on the bottom of the estuary $(1.2 \%)$ or 
were continually flowing in the water column for more than 10 days prior to the sampling $(0.8 \%)$.

The distribution of trajectories revealed mean (mean $\pm \mathrm{SD}$ ) dispersal distance, direction, and time of 2,090 $\pm 1,090 \mathrm{~m}, 152 \pm 120^{\circ}$, and $6 \pm 2 \mathrm{~h}$ (Figure 4).

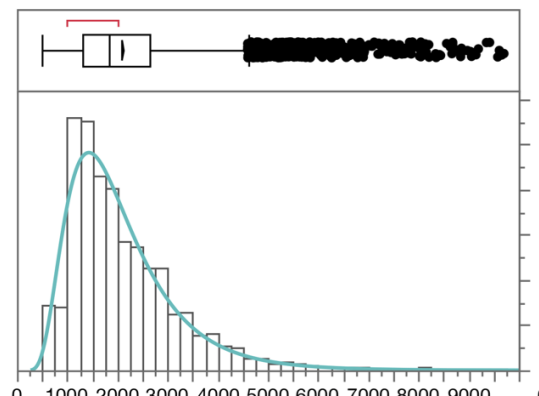

o 100020003000400050006000700080009000 distance classes [m]

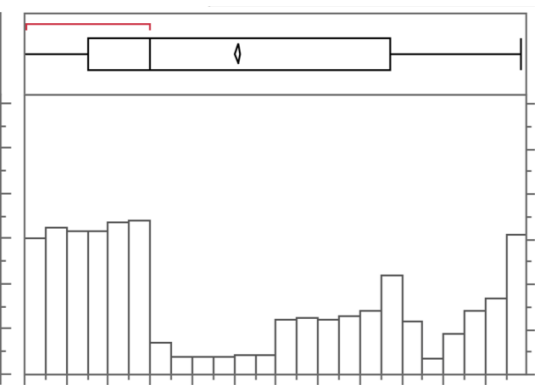

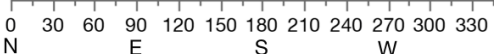
direction classes [ $\left.{ }^{\circ}\right]$

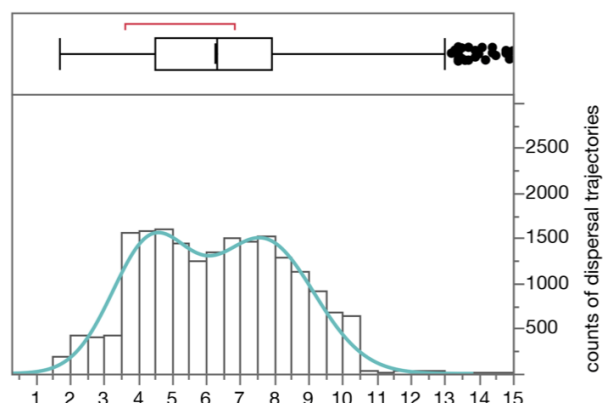

time classes $[\mathrm{h}]$

Figure 4: Distributions of dispersal distance, direction, and time of UV filters: determined by tracing water parcels back to sources in the coastline and offshore (white bars, $n=19,200$ ). Counts of dispersal trajectories are the counts over 10 days in winter, spring, summer, and fall. To facilitate visualization, dispersal distances, directions, and times are assigned to $250 \mathrm{~m}, 15^{\circ}$, and $0.5 \mathrm{~h}$ bins, respectively. For each histogram, the rectangular box plot is delimited by the lower (Q1) and upper (Q3) quartiles, and the median is represented inside the box by a straight line. Whiskers are drawn to the extreme values that are inside the fences lying at Q1 $-[1.5 \times(\mathrm{Q} 3-\mathrm{Q} 1)]$ and Q3 + [1.5 × (Q3 - Q1)]. Potential outliers are marked with black circles. Red brackets defines the shortest half of the data (the densest region). Cyan lines represent the best continuous distribution (lowest AICc value) that fits to the data.

Although dispersal distances ranged from a few hundred meters up to 10,000 m, the distribution was notably skewed, and fitted by a Johnson log-normal distribution (KomologorovSmirnov-Lilliefors test: $\mathrm{p}=0.05)$. Approximately $90 \%$ of distances were less than 3,500 m, and the shortest interval that encompassed half of the data (the densest region) ranged from 1000 to $2000 \mathrm{~m}$. Noteworthy, less than $1 \%$ of polluted water parcels reached the mussel rafts after having dispersed more than $5 \mathrm{~km}$. Conversely, dispersal directions covered the full spectrum of angles; the shortest interval that encompassed half of the data (the densest region) ranged from 345 to $90^{\circ}$ (north-northwest to east). Similar to dispersal distances, dispersal times ranged from $1 \mathrm{~h}$ up to $15 \mathrm{~h}$; the distribution was primarily binomial; and best fitted by a mixture of two normal distributions (Normal-2 Mixture distribution: $\mu_{1}=$ 
Table 1: Probability of UV filters to reach the coastline in relation to multiple independent variables. Summary of the result of a stepwise logistic model that investigated the effects of distance, direction, and all interactions.

\begin{tabular}{llllll}
\hline parameter & estimate & lower 95\% & upper 95\% & $\chi^{2}$ & prob $>\chi^{2}$ \\
\hline intercept & -6.7746 & -7.6778 & -5.9173 & 227.81 & $<0.0001$ \\
distance & 0.0027 & 0.0025 & 0.0028 & 1243.6 & $<0.0001$ \\
direction & 0.0005 & -0.0012 & 0.0023 & 0.36 & $<0.5461$ \\
\hline
\end{tabular}

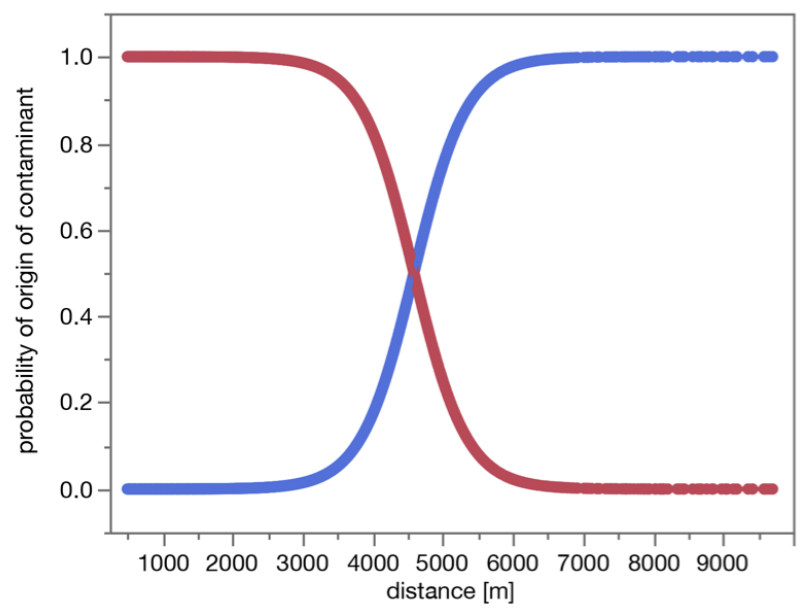

Figure 5: Probability of organic contaminant dispersal between the coastline (red curve) and raft mussels, and probability of organic contaminant dispersal between offshore locations (blue curve) and raft mussels. Curves are estimated from a logistic model (Table 1).

In contrast to the effect of distance, we found that the probability of beaching did not 
vary consistently with the direction of origin of the seawater flow (Table 1). It should be noted that it is possible that direction does not play a significant role in determining the pattern of dispersal at this small spatial scale and due to the proximity of mussel rafts to the coastline. We expect that current speeds will play a more significant role in determining the pattern of dispersal at larger spatial scales and away from the inner ria ${ }^{41}$.

\section{Effect of season and location}

Considering the effect of season on the modeled trajectories of UV filters (Figure 2), we observed that distributions of dispersal distance, direction, and time that we obtained from the trajectories were not significantly different among the four seasons (RM-PERMANOVA: global test: $p=0.12$ ). Pairwise tests for every possible combination of seasons show no significant differences between seasons for distributions of dispersal distance, direction, and time at $p<0.05$. However, the difference in the distribution of dispersal directions between winter $\left(275 \pm 95^{\circ}\right)$ and summer $\left(32 \pm 65^{\circ}\right)$ was marginally significant at $p=0.088$, and was significant at $p=0.1$. This marginal difference between the direction from which contaminants come in winter (approximately from the W) and summer (approximately from the NNE) is in agreement with the two oceanographic season in the estuary and mirrors the seasonality in wind fields and riverine outputs ${ }^{40-42}$.

Considering the effect of raft location on the modeled trajectories of UV filters, we found that distributions of dispersal distance, direction, and time were not significantly different between northern and southern sampling locations in the estuary (RM-PERMANOVA: global test: $p=0.1$. Pairwise tests show that distributions were not different between locations at $p<0.05$, with the exception of distributions of dispersal direction $p=0.001$.

Bivariate polar plots, computed for distance-direction bins, illustrate the effect of location on the envelope of distances and directions that contaminants traverse from the potential sources to the mussel rafts (Figure 6). In the northern location of the estuary, mean percentage of trajectories of waters polluted with UV filters were very high $(40 \%-50 \%)$ in the 
North to East quadrant, and pollutants came from sources located 1,900 $\pm 1000 \mathrm{~m}$ away from the mussel raft (Figure 6a). Also in the northern location, mean percentage of trajectories of waters polluted with UV filters were very high $(40 \%$ - 50\%) in the West direction, and pollutants came from sources located 1,500 $\pm 800 \mathrm{~m}$ away from the mussel raft (Figure 6a). The most probable sources of UV-filters were the coastal locations that fell within the former directions and distances, including 2 outfalls of wastewater treatment plants and 3 industrial wastewater discharges (Figure 6c). In the southern location of the estuary, mean percentage of trajectories of waters polluted with UV filters were very high $(40 \%-50 \%)$ in the Northeast direction, and pollutants came from sources located 1,800 $\pm 950 \mathrm{~m}$ away from the mussel raft (Figure 6b). Also in the southern location, mean percentage of trajectories of waters polluted with UV filters were very high (40\% - 50\%) in the West-Southwest direction, and pollutants came from sources located 1,400 $\pm 750 \mathrm{~m}$ away from the mussel raft (Figure $6 \mathrm{~b})$. The most probable sources of UV-filters are the coastal locations that fall within the former directions and distances, including 2 outfalls of wastewater treatment plants and 11 industrial wastewater discharges (Figure 6c). Noteworthy, 4 out of the 11 wastewater treatment plants (36\%) and 14 out of the 56 industrial wastewater discharges (25\%) are within the potential foci of waters parcels polluted with UV-filters. 

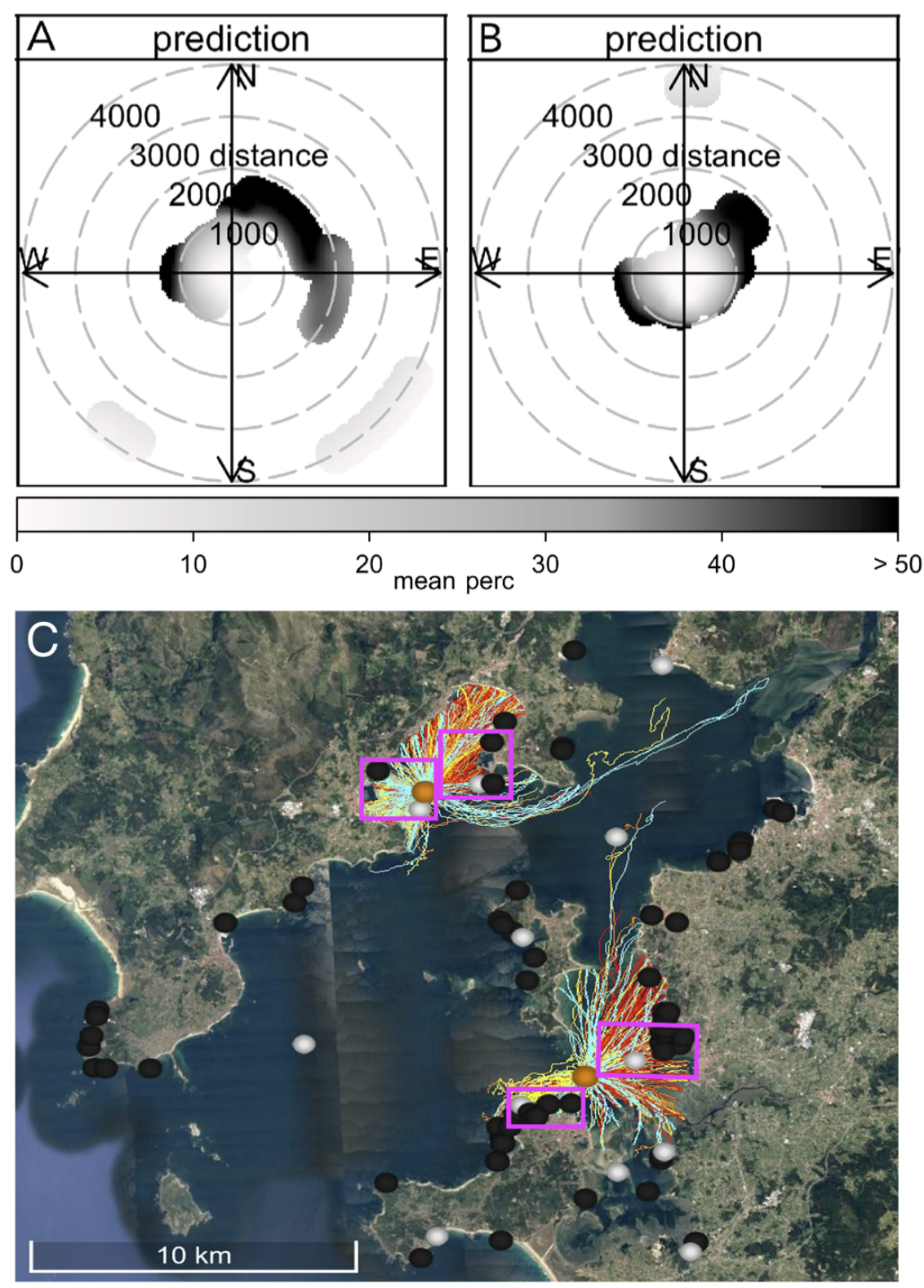

Figure 6: Bivariate polar plot of mean percentage of predicted trajectories in the northern (A) and southern (B) locations of the estuary. The key features of the northeast and southwest regions remain, suggesting that these features are "real" and not an artifact of potentially too few data. Simulated trajectories of water parcels polluted with UV filters (C) released on February (cyan), May (yellow), August (red), and November 2012 (orange). Orange, white and black circles depict the location of 2 mussel rafts, 11 wastewater treatment plants, and 56 industrial wastewater discharges. Purple rectangles depict the coastal that areas where most probable sources of UV-filters are located. 
urban wwtp

seawater $^{21}$

wwtp $^{21}$

\section{Modeled coastal concentrations and environmental implications}

To test the suitability of this model for real life applications, we computed the expected concentration of the organic UV filters 4-MBC, OC and BP-4 in the coastline and in known locations of the outfalls of wastewater treatment plants ${ }^{62}$ that received polluted water parcels after 10 days of backtracking simulation. Then we compared the expected concentrations with in situ observations of concentrations of the three UV filters in wastewater treatment plants obtained from the literature ${ }^{21}$ (Table 2 . We did not account for physicochemical processes because expected dispersal times $t$ were very short compared with half-lives obtained from level III fugacity models ${ }^{63}$.

Table 2: Minimum and maximum concentrations of organic UV filters in mussels and seawater of the sampled rafts $\left(C_{\text {mussels }}\right.$ and $C_{m}$, this study), predicted minimum and maximum concentrations in the coastline and at the outfalls of urban wastewater treatment plants $\left(C_{o}\right.$, this study), observed concentrations in seawater $\left(C_{\text {seawater-ref }}\right.$, literature $\left.{ }^{21}\right)$, and observed concentrations in wastewater treatment plants. $\left(C_{w w t p-r e f}\right.$, literature $\left.{ }^{21}\right)$

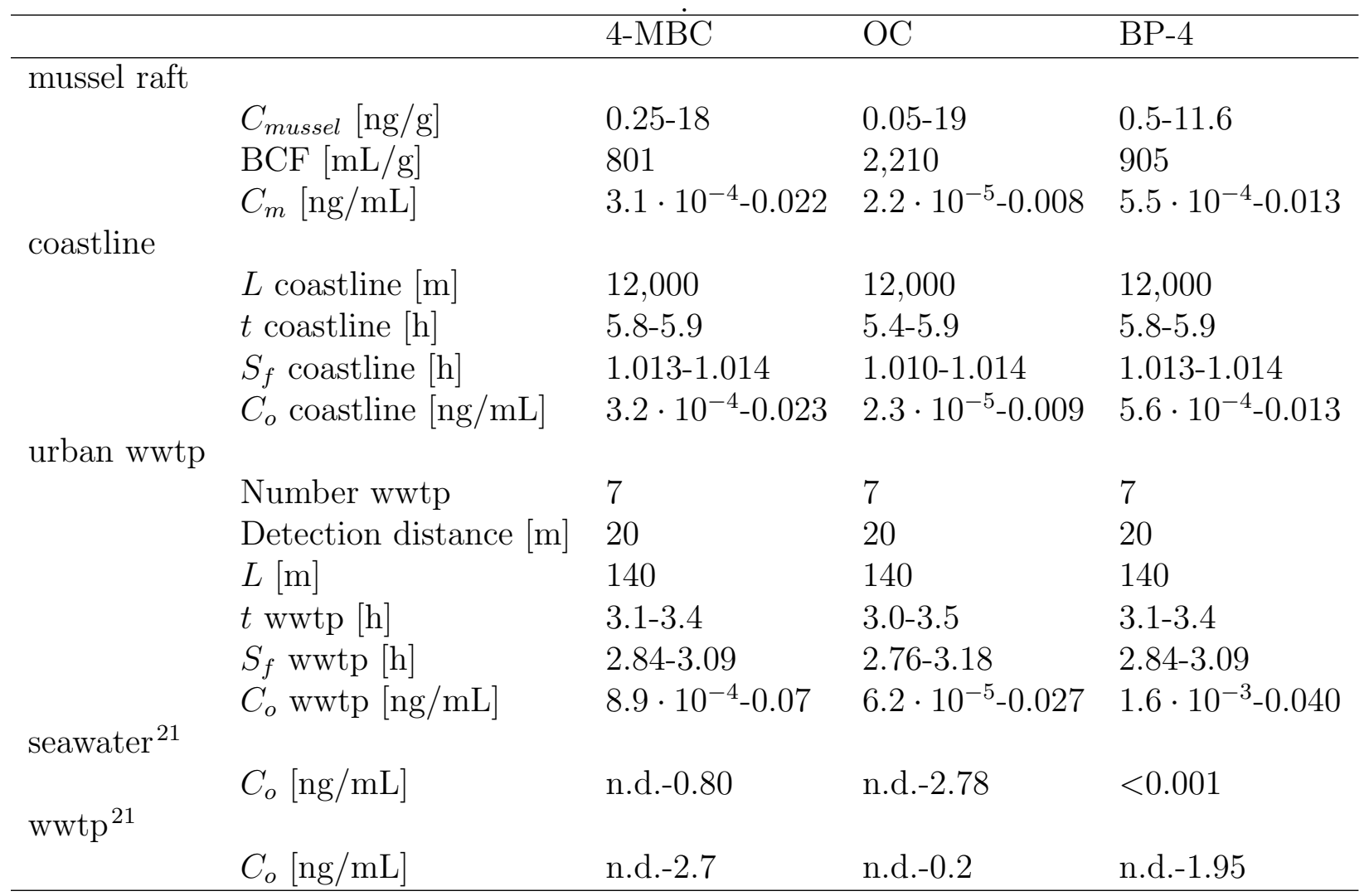


raft were $C_{m}=0.25-18 \mathrm{ng} / \mathrm{g}$ dry weight and $\mathrm{BCF}=801 \mathrm{~mL} \mathrm{~g}^{-1}$. We carried out hourly releases of 100 water parcels from the southern mussel raft located at $42.51^{\circ} \mathrm{N}, 8.85^{\circ} \mathrm{W}$ on May 14, $2012\left(C_{m}=0.25 \mathrm{ng} / \mathrm{g}\right.$, minimum $)$ and November 8, $2012\left(C_{m}=18 \mathrm{ng} / \mathrm{g}\right.$, maximum $)$ and traced them back for 10 days. The range of mean dispersal distance we obtained from tracing back all 2,400 water parcels contaminated with 4-MBC to the coastline was 1,9952,020 $\mathrm{m}$, while the mean dispersal distance we obtained from tracing back the water parcels contaminated with 4-MBC to the outfalls of wastewater treatment plants was $1,600-1,710$ m. The total distance of coastline that received polluted water parcels after 10 days of backtracking simulation (diffuser length $L$ ) was $12,000 \mathrm{~m}$. The total distance of outfalls of urban wastewater treatment plants that received polluted water parcels after 10 days of backtracking simulation (diffuser length $L$ ) was $140 \mathrm{~m}$, which was computed using a detection threshold distance of $20 \mathrm{~m}$ for each of the 7 outfalls. Using Eq. (4), Eq. (5) and Eq. (6) we derived that the concentration of $4-\mathrm{MBC}$ in the coastline and at the outfalls of urban wasterwater treatment plants were $C_{o}=3.2 \cdot 10^{-4}-0.023 \mathrm{ng} / \mathrm{mL}$ seawater and $C_{o}=8.9 \cdot 10^{-4}$ $0.07 \mathrm{ng} / \mathrm{mL}$, respectively. The upper limits of the predicted concentrations of 4 -MBC in the coastline and at the outfalls of urban wastewater treatment plants were within the ranges of the observed concentrations of $4-\mathrm{MBC}$ in seawater and in wastewater treatment plants ${ }^{21}$ (Table 2).

The range of concentrations and bioconcentration factor of $\mathrm{OC}$ in the southern mussel raft were $C_{m}=0.05-19 \mathrm{ng} / \mathrm{g}$ dry weight and $\mathrm{BCF}=2,210 \mathrm{~mL} \mathrm{~g}^{-1}$. We carried out hourly releases of 100 water parcels from the southern mussel raft located at $42.51^{\circ} \mathrm{N}, 8.85^{\circ} \mathrm{W}$ on May 14 , $2012\left(C_{m}=0.05 \mathrm{ng} / \mathrm{g}\right.$, minimum $)$ and February 2, $2012\left(C_{m}=19 \mathrm{ng} / \mathrm{g}\right.$, maximum $)$ and traced them back for 10 days. The range of mean dispersal distance we obtained from tracing back all 2,400 water parcels contaminated with OC to the coastline was 1,995-2,010 m, while the mean dispersal distance we obtained from tracing back the water parcels contaminated with OC to the outfalls of wastewater treatment plants was 1,600-1,610 m. As with 4-MBC and using Eq. (4), Eq. (5) and Eq. (6) we derived that the concentration of OC in the 
coastline and at the outfalls of urban wasterwater treatment plants were $C_{o}=2.3 \cdot 10^{-5}$ $0.009 \mathrm{ng} / \mathrm{mL}$ seawater and $C_{o}=6.2 \cdot 10^{-5}-0.027 \mathrm{ng} / \mathrm{mL}$, respectively. The upper limits of the predicted concentrations of $\mathrm{OC}$ in the coastline and at the outfalls of urban wastewater treatment plants also were within the ranges of the observed concentrations of OC in seawater and in wastewater treatment plants ${ }^{21}$ (Table 2).

The range of concentrations and bioconcentration factor of BP-4 in the southern mussel raft were $C_{m}=0.5-11.6 \mathrm{ng} / \mathrm{g}$ dry weight and $\mathrm{BCF}=905 \mathrm{~mL} \mathrm{~g}^{-1}$. We carried out hourly releases of 100 water parcels from the southern mussel raft located at $42.51^{\circ} \mathrm{N}, 8.85^{\circ} \mathrm{W}$ on May 14, $2012\left(C_{m}=0.5 \mathrm{ng} / \mathrm{g}\right.$, minimum $)$ and November 8, $2012\left(C_{m}=11.6 \mathrm{ng} / \mathrm{g}\right.$, maximum $)$ and traced them back for 10 days. The range of mean dispersal distance we obtained from tracing back all 2,400 water parcels contaminated with BP-4 to the coastline was 1,9952,020 $\mathrm{m}$, while the mean dispersal distance we obtained from tracing back the water parcels contaminated with BP-4 to the outfalls of wastewater treatment plants was 1,600-1,710 m. Using Eq. (4), Eq. (5) and Eq. (6) as in the above two target UV-filters we derived that the concentration of BP-4 in the coastline and at the outfalls of urban wasterwater treatment plants were $C_{o}=5.6 \cdot 10^{-4}-0.013$ seawater and $C_{o}=1.6 \cdot 10^{-3}-0.040 \mathrm{ng} / \mathrm{mL}$, respectively. The upper limits of the predicted concentrations of BP-4 in the coastline and at the outfalls of urban wastewater treatment plants were one order of magnitude above and within the ranges of the observed concentrations of BP-4 in seawater and in wastewater treatment plants, respectively ${ }^{21}$ (Table 2).

A question should be raised regarding the toxicological relevance of the former observed and predicted concentrations of three representative UV filters. How toxic are they for mussels and for their coastal environment? Toxicity of organic and inorganic UV filters has been demonstrated in aquatic organisms, and the occurrence of organic UV filters in molluscs has been firmly established in ecotoxicological studies (e.g., $\left.{ }^{64}\right)$. Due to their lipophilicity, these compounds tend to accumulate in muscle and adipose tissues of marine organisms ${ }^{65}$. For example, elevated concentrations of OC were found in mussels along the French coast (up 
to $7112 \mathrm{ng} / \mathrm{g} \mathrm{d.w.),} \mathrm{suggesting} \mathrm{that} \mathrm{bioaccumulation} \mathrm{of} \mathrm{organic} \mathrm{UV-filters} \mathrm{in} \mathrm{the} \mathrm{food} \mathrm{webs}$ may be happening. Accumulated UV filters could be toxic for wild mussels and other species in coastal environments ${ }^{64,66,67}$. Paredes et al. $2014^{68}$ evaluated the toxicity of 4-MBC, OC, and BP-4 in M. galloprovincialis, Paracentrotus lividus (sea urchins) and Siriella armata (crustacea). They found that 4-MBC and OC were the most toxic UV-filters whereas BP-4 presented the lowest toxicity; EC50 for 4-MBC ranged from a minimum of $192.63 \mathrm{ng} / \mathrm{mL}$ in S. armata to a maximum of $853.74 \mathrm{ng} / \mathrm{mL}$ in P. lividus ; EC50 for OC ranged from 199.43 $\mathrm{ng} / \mathrm{mL}$ in $S$. armata to $3118.18 \mathrm{ng} / \mathrm{mL}$ in M. galloprovincialis; EC50 for BP-4 was higher than $10,000 \mathrm{ng} / \mathrm{mL}$ in the three species.

Far-reaching environmental implications arise from the predicted levels of coastal concentrations of UV filters. Despite their persistence in the environment, UV filters are new from an evolutionary point of view. Biota and microorganisms have not yet adapted their metabolic pathways to efficiently degrade and remove them from the environment ${ }^{69}$. Therefore, organic UV filters also tend to accumulate in the environment, posing risk to the ecosystem and the health of biota. Notably, these substances have a natural tendency to accumulate in non-polar lipid tissues, consequently becoming persistant environmental contaminants that, biotransported through the food chain, can affect organisms on the higher trophic levels, including humans ${ }^{70}$.

In conclusion, recent advances in the field have led to the incorporation of emerging contaminants into simulation of pollutants' dispersal ${ }^{1,22}$. Using a model that has been validated from available observations helps to evaluate transport predictions and to parameterize the horizontal eddy diffusivity of the Lagrangian framework ${ }^{49}$. Our refined Lagrangian modeling approach facilitates testing chemical and physical hypotheses for the factors concomitantly influencing the pollutants dispersal, which will advance our understanding on pollution by EOCs in the estuarine environment ${ }^{8,10,14,19}$. To the best of our knowledge, this is the second model that has been implemented to understand the fate and transport of emerging contaminants in estuaries. A hydrodynamic and emerging contaminant model was implemented 
in Yangtze Estuary Reservoir and described the dynamic distributions of bisphenol-A in the reservoir ${ }^{22}$. The outcome of our study is that a Lagrangian framework is able to predict meaningful dispersal distances, dispersal times, dispersal angles, seasonal variability in transport, and concentrations of EOCs in estuarine environments. Furthermore, our results demonstrate that, in estuarine systems, physical ocean processes influence the probability that a particular dispersal trajectory will be taken. Specifically, the distance to the nearest source of contamination, the oceanographic season in the estuary, the seasonality in wind fields, and the riverine outflows are the main drivers of the transport of emerging contaminants in estuaries. Incorporating more sampling data and additional estuaries into the model ${ }^{62}$ will increase its explanatory power. Importantly, by developing a framework for testing chemical and physical hypotheses in unison, this study lays the foundation for a deeper understanding of dispersal of organic contaminants in the estuarine environment. Given the occurrence of UV filters we found in mussels; the coastal and wastewater treatment plant concentrations we modeled for 4-MBC, OC and BP-4; the known toxicity of the former UV filters in the marine environment; and their potential effects on human health, we recommend further ecotoxicological experiments, longterm exposure studies, and risk assessment of organic UV filters in estuaries: from the affected biological sinks to the modeled physical sources.

\section{Acknowledgement}

This research is supported by the Spanish State Research Agency projects CTM2014-56628C3-2-R, CTM2014-56628-C3-3-R, CTM2017-84763-C3-2-R, CTM2017-84763-C3-3-R, and CTM201790890-REDT (MINECO/ AEI/FEDER, EU). The authors thank the Galician meteorological service MeteoGalicia for providing the hydrodynamic model fields. This work used the Extreme Science and Engineering Discovery Environment (XSEDE), which is supported by the National Science Foundation grant number NSF-OCE170005. 


\title{
Supporting Information Available
}

\author{
Analytical methodology for determination of UV filters in mussels (PDF)
}

\section{References}

(1) Laender, F. D.; Hammer, J.; Hendriks, A. J.; Soetaert, K.; Janssen, C. Combining monitoring data and modeling identifies PAHs as emerging contaminants in the Arctic. Environ. Sci. Technol. 2011, 45, 9024-9029.

(2) Schnoor, J. L. Re-emergence of emerging contaminants. Environ. Sci. Technol. 2014, 48, 11019-11020.

(3) Munoz, G.; Budzinski, H.; Labadie, P. Influence of Environmental Factors on the Fate of Legacy and Emerging Per-and Polyfluoroalkyl Substances along the Salinity/Turbidity Gradient of a Macrotidal Estuary. Environ. Sci. Technol. 2017, 51, 12347-12357.

(4) Lohmann, R.; Muir, D.; Zeng, E. Y.; Bao, L.-J.; Allan, I. J.; Arinaitwe, K.; Booij, K.; Helm, P.; Kaserzon, S.; Mueller, J. F. Aquatic Global Passive Sampling (AQUA-GAPS) revisited: first steps toward a network of networks for monitoring organic contaminants in the aquatic environment. Environ. Sci. Technol. 2017, 51, 1060-1067.

(5) Barber, L. B.; Keefe, S. H.; Brown, G. K.; Furlong, E. T.; Gray, J. L.; Kolpin, D. W.; Meyer, M. T.; Sandstrom, M. W.; Zaugg, S. D. Persistence and potential effects of complex organic contaminant mixtures in wastewater-impacted streams. Environ. Sci. Technol. 2013, 47, 2177-2188.

(6) Bradley, P. M.; Journey, C. A.; Romanok, K. M.; Barber, L. B.; Buxton, H. T.; Foreman, W. T.; Furlong, E. T.; Glassmeyer, S. T.; Hladik, M. L.; Iwanowicz, L. R. Expanded target-chemical analysis reveals extensive mixed-organic-contaminant exposure in US streams. Environ. Sci. Technol. 2017, 51, 4792-4802. 
(7) Fairbairn, D. J.; Arnold, W. A.; Barber, B. L.; Kaufenberg, E. F.; Koskinen, W. C.; Novak, P. J.; Rice, P. J.; Swackhamer, D. L. Contaminants of emerging concern: mass balance and comparison of wastewater effluent and upstream sources in a mixed-use watershed. Environ. Sci. Technol. 2015, 50, 36-45.

(8) Reemtsma, T.; Berger, U.; Arp, H. P. H.; Gallard, H.; Knepper, T. P.; Neumann, M.; Quintana, J. B.; Voogt, P. d. Mind the Gap: Persistent and Mobile Organic Compounds Water Contaminants That Slip Through. Environ. Sci. Technol. 2016, 50, 10308-10315.

(9) Massei, R.; Busch, W.; Wolschke, H.; Schinkel, L.; Bitsch, M.; Schulze, T.; Krauss, M.; Brack, W. Screening of pesticide and biocide patters as risl drivers in sediments of major European rivers mouths: ubiquitous or river basin-specific contamination? Environ. Sci. Technol. 2018, 52, 2251-2260.

(10) Sun, M.; Arevalo, E.; Strynar, M.; Lindstrom, A.; Richardson, M.; Kearns, B.; Pickett, A.; Smith, C.; Knappe, D. R. Legacy and emerging perfluoroalkyl substances are important drinking water contaminants in the Cape Fear River Watershed of North Carolina. Environ. Sci. Technol. Lett. 2016, 3, 415-419.

(11) Carlson, D. L.; Vault, D. S. D.; Swackhamer, D. L. On the rate of decline of persistent organic contaminants in lake trout (Salvelinus namaycush) from the Great Lakes, 19702003. Environ. Sci. Technol. 2010, 44, 2004-2010.

(12) Richardson, S. D.; Kimura, S. Y. Water analysis: emerging contaminants and current issues. Anal. Chem. 2015, 88, 546-582.

(13) Galimany, E.; Wikfors, G. H.; Dixon, M. S.; Newell, C. R.; Meseck, S. L.; Henning, D.; Li, Y.; Rose, J. M. Cultivation of the Ribbed Mussel (Geukensia demissa) for Nutrient Bioextraction in an Urban Estuary. Environ. Sci. Technol. 2017, 51, 13311-13318.

(14) Richardson, S. D.; Temes, T. A. Water analysis: Emerging contaminants and current issues. Anal. Chem. 2018, 90, 398-428. 
(15) Chiaia-Hernandez, A. C.; Krauss, M.; Hollender, J. Screening of lake sediments for emerging contaminants by liquid chromatography atmospheric pressure photoionization and electrospray ionization coupled to high resolution mass spectrometry. Environ. Sci. Technol. 2012, 47, 976-986.

(16) Zedda, M.; Zwiener, C. Is nontarget screening of emerging contaminants by LC-HRMS successful? A plea for compound libraries and computer tools. Anal. Bioanal. Chem. 2012, 403, 2493-2502.

(17) Ismail, N. S.; Müller, C. E.; Morgan, R. R.; Luthy, R. G. Uptake of contaminants of emerging concern by the bivalves Anodonta californiensis and Corbicula fluminea. Environ. Sci. Technol. 2014, 48, 9211-9219.

(18) Loos, R.; Locoro, G.; Comero, S.; Contini, S.; Schwesig, D.; Werres, F.; Balsaa, P.; Gans, O.; Weiss, S. Pan-European survey on the occurrence of selected polar organic persistent pollutants in ground water. Water Res. 2010, 44, 4115-4126.

(19) Tiedeken, E. J.; Tahar, A.; McHugh, B.; Rowan, N. J. Monitoring, sources, receptors, and control measures for three European Union watch list substances of emerging concern in receiving waters-a 20 year systematic review. Sci. Total Environ. 2017, 574, $1140-1163$.

(20) Environmental Protection Agency (EPA),Emerging Contaminants and Federal Facility Contaminants of Concern, Technical Fact Sheets. 2018, https://www.epa.gov/fedfac/emerging-contaminants-and-federal-facilitycontaminants-concern (accessed April 20, 2018).

(21) Sánchez-Quiles, D.; Tovar-Sánchez, A. Are sunscreens a new environmental risk associated with coastal tourism? Environ. int. 2015, 83, 158-170.

(22) Xu, C.; Zhang, J.; Bi, X.; Xu, Z.; He, Y.; Gin, K. Y.-H. Developing an integrated 
3D-hydrodynamic and emerging contaminant model for assessing water quality in a Yangtze Estuary Reservoir. Chemosphere 2017, 188, 218-230.

(23) Camacho, A. P.; Labarta, U.; Beiras, R. Growth of mussels (Mytilus edulis galloprovincialis) on cultivation rafts: influence of seed source, cultivation site and phytoplankton availability. Aquaculture 1995, 138, 349-362.

(24) Pérez-Camacho, A.; Labarta, U.; Vinseiro, V.; Fernández-Reiriz, M. J. Mussel production management: raft culture without thinning-out. Aquaculture 2013, 406, 172-179.

(25) Schymanski, E. L.; Singer, H. P.; Slobodnik, J.; Ipolyi, I. M.; Oswald, P.; Krauss, M.; Schulze, T.; Haglund, P.; Letzel, T.; Grosse, S. Non-target screening with highresolution mass spectrometry: critical review using a collaborative trial on water analysis. Anal. Bioanal. Chem. 2015, 407, 6237-6255.

(26) Llorca, M.; Farré, M.; Eljarrat, E.; Díaz-Cruz, S.; Rodríguez-Mozaz, S.; Wunderlin, D.; Barcelo, D. Review of emerging contaminants in aquatic biota from Latin America: 2002-2016. Environ. Toxicol. Chem. 2017, 36, 1716-1727.

(27) Montesdeoca-Esponda, S.; Checchini, L.; Del Bubba, M.; Sosa-Ferrera, Z.; SantanaRodriguez, J. J. Analytical approaches for the determination of personal care products and evaluation of their occurrence in marine organisms. Sci. Total Environ. 2018, 633, $405-425$.

(28) Lange, M.; van Sebille, E. Parcels v0. 9: prototyping a Lagrangian ocean analysis framework for the petascale age. Geosci. Model Dev. 2017, 10, 4175-4186.

(29) van Sebille, E.; Griffies, S. M.; Abernathey, R.; Adams, T. P.; Berloff, P.; Biastoch, A.; Blanke, B.; Chassignet, E. P.; Cheng, Y.; Cotter, C. Lagrangian ocean analysis: fundamentals and practices. Ocean Model. 2017, 121, 49-75. 
(30) Lindo-Atichati, D.; Paris, C.; Le Hénaff, M.; Schedler, M.; Juárez, A. V.; Müller, R. Simulating the effects of droplet size, high-pressure biodegradation, and variable flow rate on the subsea evolution of deep plumes from the Macondo blowout. Deep Sea Res. Part 2 Top. Stud. Oceanogr. 2016, 129, 301-310.

(31) O’Driscoll, K.; Mayer, B.; Ilyina, T.; Pohlmann, T. Modelling the cycling of persistent organic pollutants (POPs) in the North Sea system: fluxes, loading, seasonality, trends. J. Mar. Syst. 2013, 111, 69-82.

(32) Wooster, W.; Bakun, A.; McLain, D. Seasonal upwelling cycle along the Eastern Boundary of the North Atlantic. J. Mar. Res. 1976, 34, 131-141.

(33) Álvarez Salgado, X.; Figueiras, F.; Pérez, F.; Groom, S.; Nogueira, E.; Borges, A.; Chou, L.; Castro, C.; Moncoiffé, G.; Ríos, A.; Miller, A.; Frankignoulle, M.; Savidge, G.; Wollast, R. The Portugal coastal counter current off NW Spain: new insights on its biogeochemical variability. Prog. Oceanogr. 2003, 56, $281-321$.

(34) Gosling, E. Marine Bivalve Molluscs; Wiley-Blackwell, 2015; Chapter 9, pp 325-382.

(35) Bermúdez, M.; Pietrzak, J. D.; Cea, L.; Puertas, J.; Stelling, G. S.; De Boer, G. J. A numerical study of mixing and stratification dynamics in the ría de Arousa estuary (NW Spain) during summer. Coastal Dynamics 2013: 7th International Conference on Coastal Dynamics, Arcachon, France, 24-28 June 2013. 2013.

(36) Cerralbo, P.; Grifoll, M.; Espino, M.; López, J. Predictability of currents on a mesotidal estuary (Ria de Vigo, NW Iberia). Ocean Dyn. 2013, 63, 131-141.

(37) Alvarez-Salgado, X.; Gago, J.; Miguez, B.; Gilcoto, M.; Pérez, F. Surface waters of the NW Iberian margin: upwelling on the shelf versus outwelling of upwelled waters from the Rias Baixas. Estuar. Coast. Shelf Sci. 2000, 51, 821-837. 
(38) Rosón, G.; Pérez, F. F.; Alvarez-Salgado, X.; Figueiras, F. Variation of both thermohaline and chemical properties in an estuarine upwelling ecosystem: Ria de Arousa; I. time evolution. Estuar. Coast. Shelf Sci. 1995, 41, 195-213.

(39) Gilcoto, M.; Álvarez-Salgado, X.; Pérez, F. Computing optimum estuarine residual fluxes with a multiparameter inverse method (OERFIM): application to the Ria de Vigo (NW Spain). J. Geophys. Res. Oceans 2001, 106, 31303-31318.

(40) Piedracoba, S.; Álvarez-Salgado, X.; Rosón, G.; Herrera, J. Short-timescale thermohaline variability and residual circulation in the central segment of the coastal upwelling system of the Ría de Vigo (northwest Spain) during four contrasting periods. J. Geophys. Res. Oceans 2005, 110, 1-15.

(41) Barton, E.; Largier, J.; Torres, R.; Sheridan, M.; Trasviña, A.; Souza, A.; Pazos, Y.; Valle-Levinson, A. Coastal upwelling and downwelling forcing of circulation in a semienclosed bay: Ria de Vigo. Prog. Oceanogr. 2015, 134, 173-189.

(42) Gilcoto, M.; Largier, J. L.; Barton, E. D.; Piedracoba, S.; Torres, R.; Graña, R.; AlonsoPérez, F.; Villacieros-Robineau, N.; Granda, F. Rapid response to coastal upwelling in a semienclosed bay. Geophys. Res. Lett. 2017, 44, 2388-2397.

(43) Costa, P.; Gómez, B.; Venâncio, A.; Pérez, E.; Pérez-Muñuzuri, V. Using the Regional Ocean Modelling System (ROMS) to improve the sea surface temperature predictions of the MERCATOR Ocean System. Sci. Mar. 2012, 76, 165-175.

(44) Shchepetkin, A. F.; McWilliams, J. C. The regional oceanic modeling system (ROMS): a split-explicit, free-surface, topography-following-coordinate oceanic model. Ocean Model. 2005, 9, 347-404.

(45) Sotillo, M. G.; Cailleau, S.; Lorente, P.; Levier, B.; Aznar, R.; Reffray, G.; AmoBaladrón, A.; Chanut, J.; Benkiran, M.; Alvarez-Fanjul, E. The MyOcean IBI Ocean 
Forecast and Reanalysis Systems: operational products and roadmap to the future Copernicus Service. J. Oper. Oceanogr. 2015, 8, 63-79.

(46) Egbert, G. D.; Erofeeva, S. Y. Efficient Inverse Modeling of Barotropic Ocean Tides. J. Atmospheric Ocean. Technol. 2002, 19, 183-204.

(47) Mateus, M.; Riflet, G.; Chambel, P.; Fernandes, L.; Fernandes, R.; Juliano, M.; Campuzano, F.; Pablo, H. d.; Neves, R. An operational model for the West Iberian coast: products and services. Ocean Sci. 2012, 10, 713-732.

(48) Pinto, L.; Mateus, M.; Silva, A. Modeling the transport pathways of harmful algal blooms in the Iberian coast. Harmful algae 2016, 53, 8-16.

(49) Lindo-Atichati, D.; Curcic, M.; Paris, C. B.; Buston, P. M. Description of surface transport in the region of the Belizean Barrier Reef based on observations and alternative high-resolution models. Ocean Model. 2016, 106, 74-89.

(50) Carvalho, J. C.; Vilhena, M. T.; Moreira, D. M. Comparison between Eulerian and Lagrangian semi-analytical models to simulate the pollutant dispersion in the PBL. Appl. Math. Model. 2007, 31, 120-129.

(51) Beron-Vera, F. J.; Wang, Y.; Olascoaga, M. J.; Goni, G. J.; Haller, G. Objective detection of oceanic eddies and the Agulhas leakage. J. Phys. Oceanogr. 2013, 43, $1426-1438$.

(52) Griffa, A. Stochastic modelling in physical oceanography; Springer, 1996; pp 113-140.

(53) LaCasce, J. Statistics from Lagrangian observations. Prog. Oceanogr. 2008, 77, 1-29.

(54) Mariano, A. J.; Griffa, A.; Özgökmen, T. M.; Zambianchi, E. Lagrangian analysis and predictability of coastal and ocean dynamics 2000. J. Atmospheric Ocean. Technol. 2002, 19, 1114-1126. 
(55) Lynch, D. R.; Greenberg, D. A.; Bilgili, A.; McGillicuddy Jr, D. J.; Manning, J. P.; Aretxabaleta, A. L. Particles in the coastal ocean: Theory and applications; Cambridge University Press, 2014.

(56) Anderson, M. J. A new method for non-parametric multivariate analysis of variance. Austral Ecol. 2001, 26, 32-46.

(57) Carslaw, D. C.; Ropkins, K. Openair-an R package for air quality data analysis. Environ. Model. Softw. 2012, 27, 52-61.

(58) Roberts, P. J.; Webster, D. R. Turbulent diffusion; ASCE Press, Reston, Virginia, 2002.

(59) Roberts, P. J. Environmental Hydraulics; Springer, 1996; pp 63-110.

(60) Brooks, N. H. Diffusion of sewage effluent in an ocean current. Waste disposal in the marine environment 1960, 246-267.

(61) Landrum, P. F.; Lydy, M. J.; Lee, H. Toxicokinetics in aquatic systems: model comparisons and use in hazard assessment. Environ. Toxicol. Chem. 1992, 11, 1709-1725.

(62) Vidal-Liñán, L.; Villaverde-de Sáa, E.; Rodil, R.; Quintana, J. B.; Beiras, R. Bioaccumulation of UV filters in Mytilus galloprovincialis mussel. Chemosphere 2018, 190, $267-271$.

(63) Pence, H. E.; Williams, A. ChemSpider: an online chemical information resource. J. Chem. Educ. 2010, 8\%, 1123-1124.

(64) Bachelot, M.; Li, Z.; Munaron, D.; Le Gall, P.; Casellas, C.; Fenet, H.; Gomez, E. Organic UV filter concentrations in marine mussels from French coastal regions. Sci. Total Environ. 2012, 420, 273-279.

(65) Gago-Ferrero, P.; Diaz-Cruz, M. S.; Barceló, D. An overview of UV-absorbing compounds (organic UV filters) in aquatic biota. Anal. Bioanal. Chem. 2012, 404, 25972610. 
(66) Nakata, H.; Murata, S.; Filatreau, J. Occurrence and concentrations of benzotriazole UV stabilizers in marine organisms and sediments from the Ariake Sea, Japan. Environ. Sci. Technol. 2009, 43, 6920-6926.

(67) Kim, J.-W.; Isobe, T.; Ramaswamy, B. R.; Chang, K.-H.; Amano, A.; Miller, T. M.; Siringan, F. P.; Tanabe, S. Contamination and bioaccumulation of benzotriazole ultraviolet stabilizers in fish from Manila Bay, the Philippines using an ultra-fast liquid chromatography-tandem mass spectrometry. Chemosphere 2011, 85, 751-758.

(68) Paredes, E.; Perez, S.; Rodil, R.; Quintana, J.; Beiras, R. Ecotoxicological evaluation of four UV filters using marine organisms from different trophic levels Isochrysis galbana, Mytilus galloprovincialis, Paracentrotus lividus, and Siriella armata. Chemosphere 2014, 104, 44-50.

(69) Janssen, D. B.; Dinkla, I. J.; Poelarends, G. J.; Terpstra, P. Bacterial degradation of xenobiotic compounds: evolution and distribution of novel enzyme activities. Environ. Microbiol. 2005, \%, 1868-1882.

(70) Rainieri, S.; Barranco, A.; Primec, M.; Langerholc, T. Occurrence and toxicity of musks and UV filters in the marine environment. Food Chem. Toxicol. 2017, 104, 57-68. 


\section{Graphical TOC Entry}

684

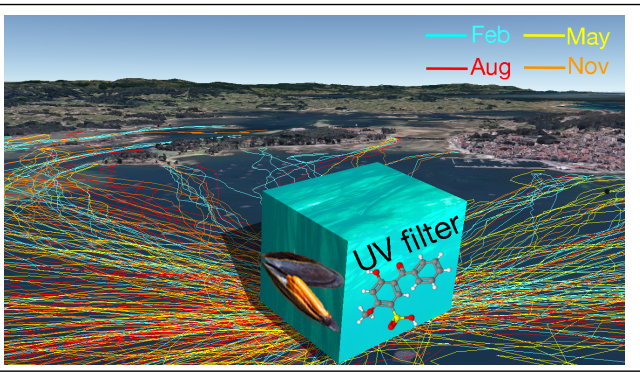




\section{Supporting information}

$$
\text { for }
$$

\section{Modeling dispersal of UV filters in estuaries}

David Lindo-Atichati, ${ }^{*}$,, , Pedro Montero, ${ }^{\S}$ Rosario Rodil, José Benito Quintana," and Manuel Miró ${ }^{\perp}$

†Department of Applied Ocean Physics and Engineering, Woods Hole Oceanographic Institution, Woods Hole, MA USA

Department of Earth and Planetary Sciences, American Museum of Natural History, New York, NY USA

"Department of Engineering Science and Physics, The City University of New York, Staten Island, NY USA

IINTECMAR, Xunta de Galicia, Vilagarcía de Arousa, Spain

'Department of Analytical Chemistry, University of Santiago de Compostela, Santiago de Compostela, Spain

${ }^{\perp}$ FI-TRACE group, Department of Chemistry, University of the Balearic Islands, Carretera de Valldemossa km 7.5, E-07122 Palma de Mallorca, Spain

E-mail: dlindo@whoi.edu 


\section{Analytical methodology for determination of UV filters in mussels}

UV filters were extracted from mussels (in every sampling location and time) by matrix solid-phase dispersion. To this end, $0.5 \mathrm{~g}$ of freeze-dried molluses were thoroughly homogenized in a glass mortar with $0.2 \mathrm{~g}$ of diatomaceous earth, used as a solid support. A $10 \mathrm{~mL}$ syringe barrel, furnished with a polymeric frit at the bottom, was subsequently filled with $1.0 \mathrm{~g}$ of $\mathrm{Na}_{2} \mathrm{SO}_{4}, 4.0 \mathrm{~g}$ of silica gel, the homogenized sample and finally topped with a second frit. Then, the analytes were eluted with $20 \mathrm{~mL}$ of acetonitrile. The eluate was concentrated to a final volume of $0.5 \mathrm{~mL}$ because extract dryness should be avoided. Finally, the extract was filtrated through a $0.22 \mu \mathrm{m}$ PVDF syringe filter (MerckMillipore, Darmstadt, Germany). Quantification was performed by the standard addition method. This was carried out by dividing the $500 \mu \mathrm{L}$ extract in four aliquots, which were spiked each with increasing amounts of the three analytes.

UV filters in the extracts were analyzed by a liquid chromatographic (LC) system, which was composed of (i) two ProStar 210 high-pressure mixing pumps (Varian, Walnut Creek, CA, USA), (ii) a Metachem Technologies (Bath, UK) vacuum membrane degasser, (iii) an autosampler and (iv) a thermostated column compartment ProStar 410 module (Varian). The LC was coupled to a triple quadrupole mass spectrometer (LCQqQ-MS, Varian 340-MS) which incorporates an electrospray interface (ESI). The determination of UV filters was performed by recording two transitions for each analyte in the multiple reaction monitoring (MRM) mode. Specific ESI-MS/MS parameters for each analyte are as follows: BP-4 307 $\rightarrow 211$ and $307 \rightarrow 227$ in negative mode; 4-MBC $255 \rightarrow 105$ and $255 \rightarrow 212$ in positive mode and OC $362 \rightarrow 232$ and $362 \rightarrow 250$ in positive mode. 